\title{
Correlation of Global Solar Radiation of Eight Synoptic Stations in Burkina Faso Based on Linear and Multiple Linear Regression Methods
}

\author{
Ousmane Coulibaly $^{1}$ and Abdoulaye Ouedraogo ${ }^{2}$ \\ ${ }^{1}$ Laboratoire de Physique et Chimie de l'Environnement (LPCE), Unité de Formation et de Recherche en Sciences \\ Exactes et Appliquée, Université de Ouagadougou, 03 BP 7021, Ouagadougou 03, Burkina Faso \\ ${ }^{2}$ Unité de Formation et de Recherche en Sciences Exactes et Appliquée, Université de Ouagadougou, 03 BP 7021, \\ Ouagadougou 03, Burkina Faso
}

Correspondence should be addressed to Ousmane Coulibaly; coulous2005@yahoo.fr

Received 7 August 2015; Revised 11 December 2015; Accepted 31 January 2016

Academic Editor: Yoji Saito

Copyright (C) 2016 O. Coulibaly and A. Ouedraogo. This is an open access article distributed under the Creative Commons Attribution License, which permits unrestricted use, distribution, and reproduction in any medium, provided the original work is properly cited.

\begin{abstract}
We utilize the multiple linear regression method to analyse meteorological data for eight cities in Burkina Faso. A correlation between the monthly mean daily global solar radiation on a horizontal surface and five meteorological and geographical parameters, which are the mean daily extraterrestrial solar radiation intensity, the average daily ratio of sunshine duration, the mean daily relative humidity, the mean daily maximum air temperature, and the sine of the solar declination angle, was examined. A second correlation is established for the entire country, using, this time, the monthly mean global solar radiation on a horizontal surface and the following climatic variables: the average daily ratio of sunshine duration, the latitude, and the longitude. The results show that the coefficients of correlation vary between 0.96 and 0.99 depending on the station while the relative errors spread between $-3.16 \%$ (Pô) and 3.65\% (Dédougou). The maximum value of the RMSD which is $312.36 \mathrm{~kJ} / \mathrm{m}^{2}$ is obtained at Dori, which receives the strongest radiation. For the entire cities, the values of the MBD are found to be in the acceptable margin.
\end{abstract}

\section{Introduction}

The quantification of the solar energy potential depends on many parameters such as the availability, the number and location of synoptic stations, and the utilization of adequate formalism for its evaluation. A review of solar radiation models [1] and measurement techniques [2] are presented by Pandey and Katiyar. They noted that the first correlation has been suggested by Angstrom [3]; it relates the global solar radiation to sunshine duration. The modification of the Angstrom relation has been made by Page [4] and Prescott [5]. Afterwards, many other researches have been accomplished in specific countries throughout the world, for example, in Romania [6], in Malaysia [7], in Iran [8], in China [9], and in Ghana [10]. In 2006, some of these countries have been compiled by Skeiker [11]. Many investigators [12, 13] have utilized the latitude and the solar declination. Yet others have introduced geographical and meteorological parameters [14-16]. Recently, Dumas et al. presented a new correlation between global solar energy radiation and daily temperature variations [17].

In Burkina Faso, preliminary investigations have been made by Garané [18] and Baldy [19] who established a correlation between the solar radiation and the sunshine duration spanning from 1971 to 1990 (Garané) and 1971 to 1975 (Baldy) for five cities. In the present study, we look forward to extending the early investigations by determining first of all the coefficients of the modified Angstrom correlation, noted as $a$ and $b$ for eight cities. Next, we seek to establish, successively, correlation relations between the global radiation and five climatic variables for the eight cities. Finally the monthly mean global solar radiation on a horizontal surface 
TABLE 1: Geographical locations of the eight cities of concern [20].

\begin{tabular}{lcccccccc}
\hline Cities & Ouaga & Dori & Bobo & Gaoua & Fada & Boromo & Pô & Dédougou \\
\hline Latitude (N) & $12^{\circ} 21^{\prime}$ & $14^{\circ} 02^{\prime}$ & $11^{\circ} 11^{\prime}$ & $10^{\circ} 20^{\prime}$ & $12^{\circ} 02^{\prime}$ & $11^{\circ} 45^{\prime}$ & $11^{\circ} 10^{\prime}$ & $12^{\circ} 28^{\prime}$ \\
Longitude (W) & $01^{\circ} 31^{\prime}$ & $00^{\circ} 02^{\prime}$ & $04^{\circ} 19^{\prime}$ & $03^{\circ} 11^{\prime}$ & $00^{\circ} 22^{\prime} \mathrm{E}$ & $02^{\circ} 56^{\prime}$ & $01^{\circ} 09^{\prime}$ & $03^{\circ} 29^{\prime}$ \\
Altitude (m) & 296 & 277 & 432 & 333 & 308 & 270 & 326 & 308 \\
\hline
\end{tabular}

and the following climatic variables, the average daily ratio of sunshine duration, the latitude, and the longitude, would be investigated.

\section{Equipment and Data Collection}

2.1. Equipment Setup and Data Acquisition. The sunshine durations are meteorological data and are measured by a heliograph of Campbell-Stokes type, designed by CASELLA. The data acquisition process is made according to the world organization of meteorology standards from heliograph bands. The global radiation is measured utilizing KIPP and ZONEN Pyranometer with numerical ELSB-2 integrators, which integrates the values of the daily solar radiation. Two stations, Dédougou and Fada N'gourma, are equipped with pyranometer-integrator of CIMEL type, which integrates the hourly values of the global solar radiation intensity. The apparatuses are installed on concrete construction approximately 1.5 meter in height in places released, in order to avoid the shadow of the surrounding objects. Table 1 indicates the latitude, the longitude, and the altitude of the eight stations of concern. Data for global solar radiation, sunshine duration, the maximum temperature, and relative humidity have been collected for all cities, from 1977 to 2006 [20].

\subsection{Estimation of the Extraterrestrial Solar Radiation on a} Horizontal Surface $\left(H_{o}\right)$ and the Maximum Sunshine Duration. The extraterrestrial radiation on a horizontal surface $\left(H_{o}, \mathrm{~kJ} / \mathrm{m}^{2}\right)$ is determined utilizing the following relation [2123]. Indeed the measurement data of global solar radiation provided by the national meteorological service are in $\mathrm{kJ} / \mathrm{m}^{2}$. Consider

$$
\begin{aligned}
H_{o}= & 3.795 \\
& \cdot 10^{4} \cos (\phi) \cos (\delta)\left[\sin \left(\omega_{s}\right)-\frac{\pi \omega_{s}}{180} \cos \left(\omega_{s}\right)\right] .
\end{aligned}
$$

The quantity $3.795 \cdot 10^{4}$ given by Jannot [22] to convert the extraterrestrial radiation into $\mathrm{kJ} / \mathrm{m}^{2}$ comes from the term $(24 / \pi) * I_{0}$. The value of the solar constant $I_{0}$ used by Jannot is $1380 \mathrm{~W} / \mathrm{m}^{2}$. This quantity takes into account the eccentricity correction factor of Earth's orbit which is calculated using the following relation:

$$
C=1+0.034 \cos [30(m-1)+d] .
$$

In relations (2) and (4), $m$ is the number of the month in the year starting with January and $d$ the number of the day in the month. Let us announce that, by carrying out the calculation programme under the Matlab software, we took account of conversions on each time the need is essential.
In relations (1) and (3) $\phi$ is the latitude; $\omega_{s}$ is the solar angle of the sundown, obtained from the next relation:

$$
\omega_{s}=\operatorname{arcos}(-\tan (\phi) \tan (\delta)) \text {. }
$$

$\delta$ is the declination which is inferred from the following equation:

$$
\delta=23.45^{\circ} \cos (30 m+d-202) .
$$

We also define the hour angle $\omega$ as follows:

$$
\omega\left(^{\circ}\right)=-15^{\circ}\left(12-T_{s}\right),
$$

where $T_{s}$ is the solar hour of the day. The hour angle $\omega_{c}$ at sunset is opposite to its sundown equivalent; therefore, $\omega_{c}=$ $-\omega_{l}$.

The solar hour at sunrise is given by

$$
\left(T_{s}\right)_{l}=12-\frac{\omega_{s}}{15}
$$

At sunset the equivalent solar hour becomes

$$
\left(T_{s}\right)_{c}=12+\frac{\omega_{s}}{15}
$$

We can then infer the maximum daily sunshine duration as follows:

$$
N=\frac{2 \omega_{s}}{15}
$$

\section{Estimation of the Regression Coefficients}

First of all, we averaged, over one-year interval, the global radiation $(H)$ and the sunshine duration data collected by the national meteorological service from 1992 to 2006. Next, we estimate the extraterrestrial radiation on a horizontal surface $\left(H_{o}\right)$ and the maximum sunshine duration $(N)$ for each station for the entire year. Finally, a linear relation of Angstrom type is utilized for a correlation between the index of clearness $\left(\mathrm{H} / \mathrm{H}_{\mathrm{o}}\right)$ and the daily ratio of sunshine duration $(n / N)$. [3]

Now, let us recall the original Angstrom formula which is

$$
H=H_{o}^{\prime}\left(a^{\prime}+b^{\prime} \frac{n}{N}\right)
$$

where $n$ is the number of hours of daily sunshine duration, $N$ is the maximum number of hours of daily sunshine duration, $H$ is the daily global radiation on a horizontal surface, $H_{o}^{\prime}$ is the daily global radiation on a horizontal surface by clear sky, and $a^{\prime}$ and $b^{\prime}$ are coefficients to be determined. 
In the original Angstrom formula (9), $H_{o}^{\prime}$ is found to be difficult to determine. Thus, Page [4] and Prescott [5] formulated a modified relation in a manner that the extraterrestrial radiation on a horizontal surface $H_{o}$ appears; that is,

$$
H=H_{o}\left(a+b \frac{n}{N}\right) .
$$

Here, $a$ and $b$ are constants to be determined experimentally for each region.

We rewrite relation (10) in a more useful form as follows:

$$
\frac{H}{H_{o}}=a+b \frac{n}{N} .
$$

In this relation, the ratio $H / H_{o}$ usually denoted by $K_{T}$ is known as the index of clearness. It is an indication of the degree of purity of the atmosphere; it indicates the presence of aerosols or water molecules in the atmosphere. The ratio $n / N$ is the fraction of sunshine duration, expressed as the quotient of the actual $(n)$ divided by the theoretical $(N)$ sunshine duration. The coefficients $a$ and $b$ are obtained by drawing the fraction of sunshine duration as a function of the index of clearness; then, $a$ is the ordinate and is an indication of the value of the fraction of the incident radiation for a covered sky; $b$, on the other hand, is the slope of the regression line. The sum $(a+b)$ gives an indication on the transmissivity of the atmosphere in condition of clear sky [18].

For each city, a correlation is established between the global solar radiation on a horizontal surface and five meteorological parameters, which are the mean daily extraterrestrial solar radiation intensity, the average daily ratio of sunshine duration, the mean daily relative humidity, the mean daily maximum air temperature, and the sine of the solar declination angle. For the entire country, a correlation is realized involving the index of clearness, the average daily ratio of sunshine duration, and the latitude and longitude. For the relations of correlation involving many parameters, we have utilized a multiple linear regression suggested by Skeiker [11]:

$$
y=c+d x_{1}+e x_{2}+f x_{3}+g x_{4}+h x_{5},
$$

where $c, d, e, f, g, h$ are the regression coefficients and $x_{1}$, $x_{2}, x_{3}, x_{4}, x_{5}$ the correlation parameters. The relative error between the measured and estimated quantities is calculated from the following relation:

$$
e=\left[\frac{\left(\bar{H}_{i, m}-\bar{H}_{i, c}\right)}{\overline{H_{i, m}}}\right] \cdot 100,
$$

where $\bar{H}_{i, m}$ is the monthly average of daily global radiation measured over a horizontal surface for the $i$ th month and $\bar{H}_{i, c}$ is its value obtained from the relation of correlation. Usually, a precision in the interval of $-10 \%$ to $10 \%$ is acceptable, Skeiker [11]. For the same purpose, we can also compute statistical test parameters such as the root mean square differences (RMSD)

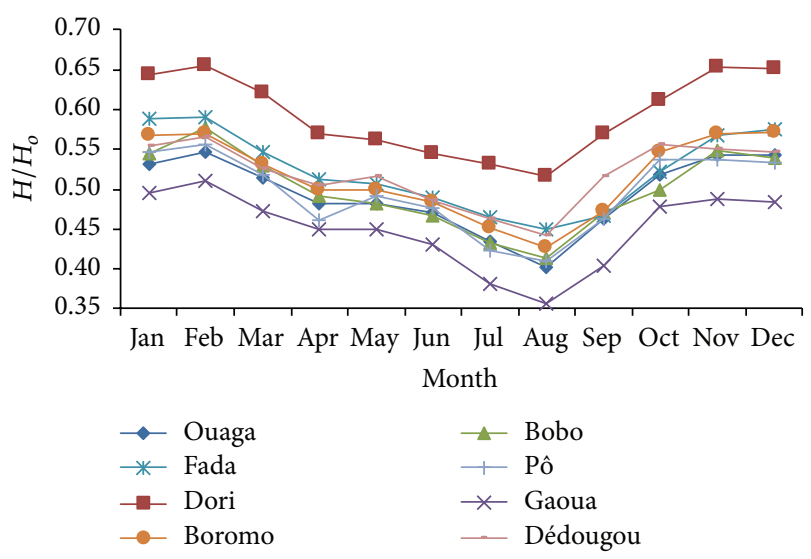

FIGURE 1: Indexes of clearness for the eight synoptic stations.

and the mean bias differences (MBD), given by the following relations:

$$
\operatorname{RMSD}=\left(\frac{1}{n} \sum_{i=1}^{n}\left(\bar{H}_{i, m}-\bar{H}_{i, c}\right)^{2}\right)^{1 / 2} .
$$

Equation (14) provides information on the short term performances of the correlations by allowing a term by term comparison between the calculated and the measured values. The smaller the deviations are the better the model's performances are. Consider

$$
\mathrm{MBD}=\frac{1}{n} \sum_{i=1}^{n}\left(\bar{H}_{i, m}-\bar{H}_{i, c}\right) .
$$

The above test relation provides information on the long term performance. A low MBD is desired. A positive value gives the average amount of underestimation in the calculated value and vice versa. A drawback of this test is that overestimation of an individual observation will cancel underestimation in a separate observation.

On the other hand, the performance of the model is tested by the following statistical equation:

$$
t=\left[\frac{(n-1) \mathrm{MBD}^{2}}{\mathrm{RMSD}^{2}-\mathrm{MBD}^{2}}\right]^{1 / 2} .
$$

The smaller the value of $t$, the better the model's performance. The critical quantity is calculated at $t_{\alpha / 2}$ where $\alpha$ is the level of significance and $(n-1)$ the degrees of freedom. The degree of confidence is about $95 \%$, which sets $\alpha=5 \%$ and $\alpha / 2=2.5 \%$.

\section{Results and Discussion}

4.1. Index of Clearness and Daily Ratio of Sunshine Duration. Figure 1 indicates the mean values of the indexes of clearness for the eight synoptic stations. The indexes are comprised between 0.36 and 0.66 which indicates that the atmosphere contains impurities all year long. The lowest value is obtained at Gaoua, a region with a tradition of relatively heavy rainfall. This lowest index is, therefore, due to the albedo of the cloud 
TABLE 2: Statistics of regression with modified Angstrom model: comparison of the results obtained by the current investigation with those of other investigations.

\begin{tabular}{|c|c|c|c|c|c|c|c|c|c|c|c|c|}
\hline \multirow{3}{*}{ Town } & \multicolumn{9}{|c|}{ Regression coefficients $a, b$} & \multicolumn{3}{|c|}{$R$} \\
\hline & & $a$ & & & $b$ & & & $a+b$ & & & & \\
\hline & $(1)$ & (2) & $(3)$ & (1) & (2) & (3) & (1) & (2) & $(3)$ & $(1)$ & (2) & (3) \\
\hline Dori & 0.13 & 0.14 & 0.24 & 0.62 & 0.58 & 0.52 & 0.75 & 0.72 & 0.76 & 0.95 & 0.84 & $>90$ \\
\hline Fada N'Gourma & 0.21 & 0.20 & 0.26 & 0.45 & 0.49 & 0.48 & 0.66 & 0.69 & 0.74 & 0.91 & 0.71 & $>90$ \\
\hline Ouagadougou & 0.17 & 0.22 & 0.27 & 0.47 & 0.45 & 0.48 & 0.64 & 0.67 & 0.75 & 0.95 & 0.90 & $>90$ \\
\hline Bobo Dioulasso & 0.21 & 0.26 & 0.31 & 0.46 & 0.43 & 0.48 & 0.67 & 0.69 & 0.79 & 0.90 & 0.79 & $>90$ \\
\hline Gaoua & 0.15 & 0.22 & 0.26 & 0.46 & 0.46 & 0.48 & 0.61 & 0.68 & 0.74 & 0.96 & 0.92 & $>90$ \\
\hline Boromo & 0.18 & - & - & 0.53 & - & - & 0.71 & - & - & 0.97 & - & - \\
\hline Pô & 0.21 & - & - & 0.43 & - & - & 0.64 & - & - & 0.93 & - & - \\
\hline Dédougou & 0.23 & - & - & 0.4 & - & - & 0.63 & - & - & 0.91 & - & - \\
\hline Burkina Faso & 0.18 & 0.23 & 0.26 & 0.49 & 0.44 & 0.42 & 0.67 & 0.67 & 0.68 & 0.81 & 0.78 & - \\
\hline
\end{tabular}

(1) Results obtained by the actual investigation.

(2) Results obtained by Garané J. Ali, Period: 1971-1990.

(3) Results obtained by Baldy, Period: 1971-1975.

and the presence of water molecules in the atmosphere. The highest index, 0.66 , is obtained at Dori, a city located at the northern tip of the country, with scarce rainfalls. For all eight stations, the highest values are observed between the months of November and February. This period corresponds to the dry season with no cloud in the sky. However, the 0.66 index is an indication of the presence of impurities in the atmosphere which is due to the important phenomenon of absorption and diffusion of solar radiation by the aerosol particles. During this period, the strong winds of harmattan, carrying dust, sand, and many other small objects, feed the atmosphere with aerosol particles of all sizes. Indeed, Latha and Badarinath [24] have noticed that the concentration of aerosol particles of sizes $\mathrm{PM}_{10}$ and $\mathrm{PM}_{2.5}$ is strong during the same period (harmattan) and weak on the other hand, during June to October (monsoon) in urban area in tropical regions. At Gaoua, Fada and Bobo, Pô, and Boromo, the permanence and the concentration of the clouds during the month of August explain the strong drop of the indexes of clearness. On the contrary, the increase during the month of October is due to the purity of the atmosphere just after the end of the raining season, Figure 2 . The daily ratio of sunshine duration varies between 0.45 and 0.86 and represents the ratio of the real sunshine duration $(n)$ and the theoretical sunshine duration $(N)$, the national mean value being 0.68 . Towns with lower latitudes have lower value of the daily ratio of sunshine duration, once again due to the heavy rainfalls which shorten the sunshine duration.

4.2. The Regression Coefficients of the Modified Angstrom's Relation. We show in Table 2 the results of this research based on the relation of Angstrom. For all the stations, the correlation coefficient $R$ is greater than 0.90 . We next compare the actual coefficients with the preliminary results established by Garané [18] and Baldy [19] for five stations.

The values of $(a+b)$ are quite similar. For the values obtained throughout the country, the coefficient $(a)$ rather decreases from $(3)^{c}$ to $(1)^{a}$ and $(b)$ increases somehow in

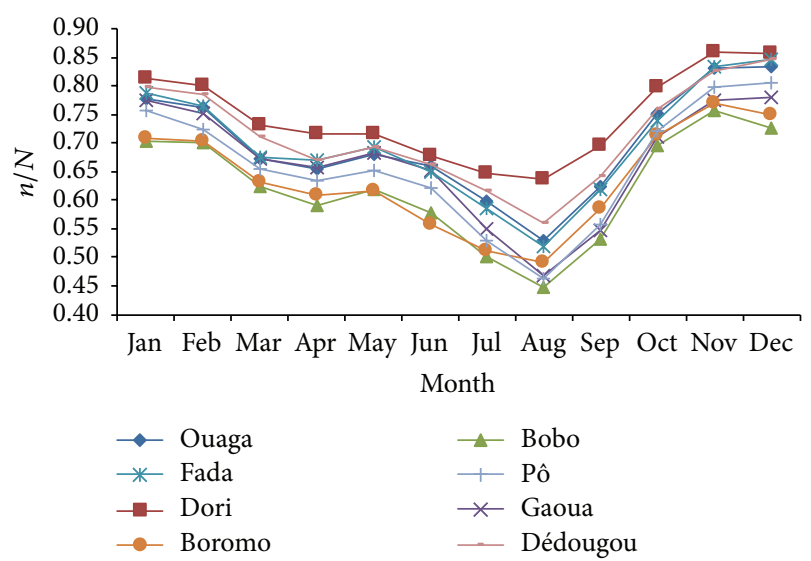

FIGURE 2: Daily ratio of sunshine duration for the eight synoptic stations.

the same period from $(3)^{c}$ to $(1)^{a}$. This is an indication of the presence of aerosols in the atmosphere. The values of the correlation coefficients $R$ which are greater than 0.90 for all cities tend to indicate good correlations between the global radiation and the sunshine duration. On the other hand, the mean value of 0.81 for the entire country is a good indication of the disparities between the radiation intensities of the regions due to the latitude, especially when we move from north to south. We present next the correlation results when we take into account the latitude and longitude.

4.3. Correlation of the Radiation Intensity for the Eight Synoptic Stations. Table 3 shows the regression and correlation coefficients obtained for each synoptic station. Substituting the correlation parameters $x_{1}, x_{2}, x_{3}, x_{4}$, and $x_{5}$ in relation (12), respectively, by $\overline{H_{\mathrm{o}}}, \bar{n} / \overline{\mathrm{N}},{\overline{H_{r}}}_{\mathrm{T}_{\text {max }}}$, and $\sin \delta$, we obtain the following:

$$
\bar{H}=c+d \overline{H_{o}}+e \frac{\bar{n}}{N}+f{\overline{H_{r}}}+g \bar{T}_{\max }+h \sin \delta .
$$


TABLE 3: Regression and correlation coefficients for the eight synoptic stations.

\begin{tabular}{lccccccc}
\hline \multirow{2}{*}{ Town } & \multicolumn{4}{c}{ Regression coefficients } & \multicolumn{2}{c}{ Correlation coefficients $R$} \\
& $c$ & $d$ & $e$ & $f$ & $g$ & $h$ & 0.9921 \\
Ouagadougou & -42029.17 & 1.47 & 28272.41 & -52.34 & -288.51 & -7159.12 & 0.9663 \\
Dori & -29708.40 & 1.18 & 24708.40 & -42.67 & -215.96 & -5665.02 & 0.9716 \\
Bobo & -25348.65 & 1.25 & 19467.64 & -70.46 & -300.73 & -4966.91 & 0.9703 \\
Fada & -12528.50 & 0.84 & 11913.21 & -53.95 & -132.42 & -2794.62 & 0.9718 \\
Boromo & -18674.15 & 0.88 & 26336.83 & -53.52 & -239.08 & - & 0.9958 \\
Gaoua & -32597.17 & 1.18 & 22393.81 & -29.37 & -204.06 & -6080.06 & 0.9661 \\
Pô & -58512.29 & 2.31 & 41061.96 & -89.36 & -843.51 & -10586.65 & 0.9782 \\
Dédougou & -58791.68 & 1.76 & 36191.21 & -13.37 & -298.69 & -9805.01 & \\
\hline
\end{tabular}

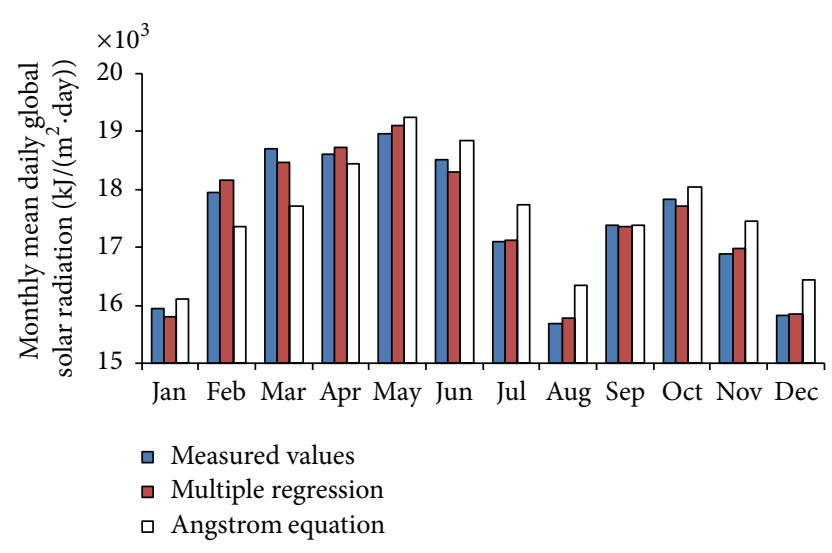

FIGURE 3: Comparison between measured and correlated values at Ouagadougou.

Hence, for a given station, the correlation between the global radiation on a horizontal surface and the five parameters is obtained by replacing the regression coefficients $c, d, e, f, g$, and $h$ with their respective numerical values.

The values of the regression coefficients $c, d, e, f, g$, and $h$ vary both with and within the same location. The study of Skeiker [11] showed that when the number of regression coefficients, for the multiple linear regression models, is higher results obtained are better. The correlation obtained is nevertheless good between the parameters. The lowest value of the correlation coefficient $R$ is obtained at Pô $(R=0.9661)$ while the highest is reached at Gaoua $(R=0.9958)$. For the city of Boromo, a correlation is established between the monthly mean daily global solar radiation on a horizontal surface and four parameters because the coefficient " $h$ " shows a different behavior to the rest of the city when we take into account the solar declination angle.

We compare in the following, Figures 3-6, the measured solar radiation intensity, its estimated values obtained from the Angstrom relation, and the results obtained from the correlations based on the five meteorological parameters. The figures clearly show two picks corresponding to two hot seasons, respectively, from March to June and in October. As for the indexes of clearness and the ratio of sunshine duration, the lowest radiation values are observed during the raining season.

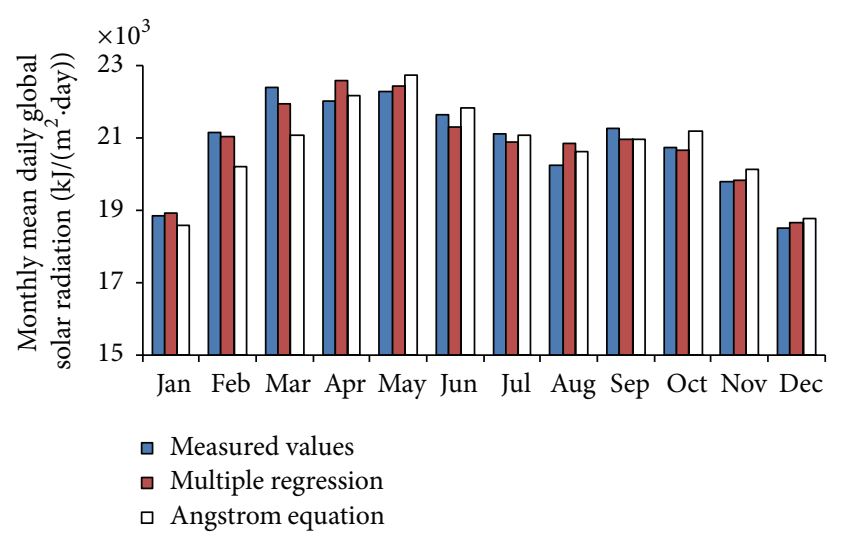

FIGURE 4: Comparison between measured and correlated values at Dori.

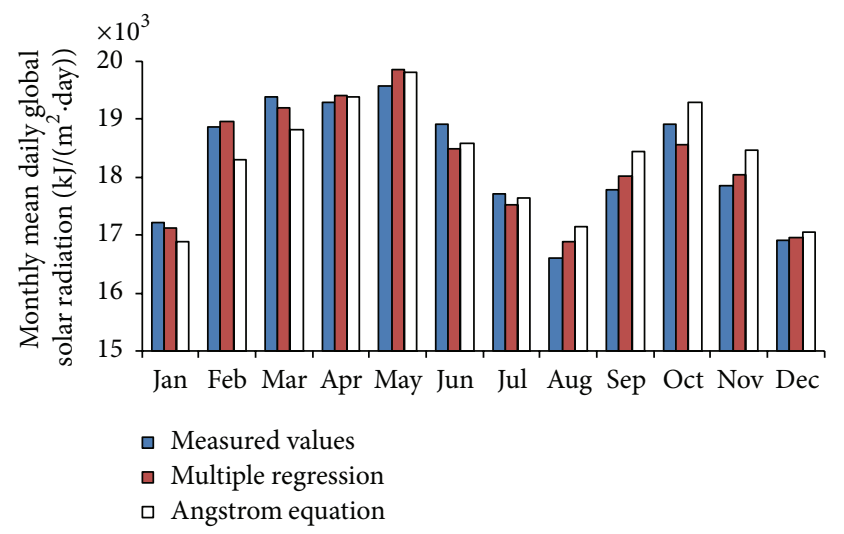

FIgURE 5: Comparison between measured and correlated values at Boromo.

The histograms show clearly when comparing the measured and the correlation values with the Angstrom relation results that the meteorological parameters (humidity, temperature, and declination) have an influence on the global radiation intensity received by a horizontal surface. Tables 4(a) -4 (d) display the values of the measured global radiation and the correlated values based on the five meteorological parameters. We present also the statistical parameters obtained in each case. 


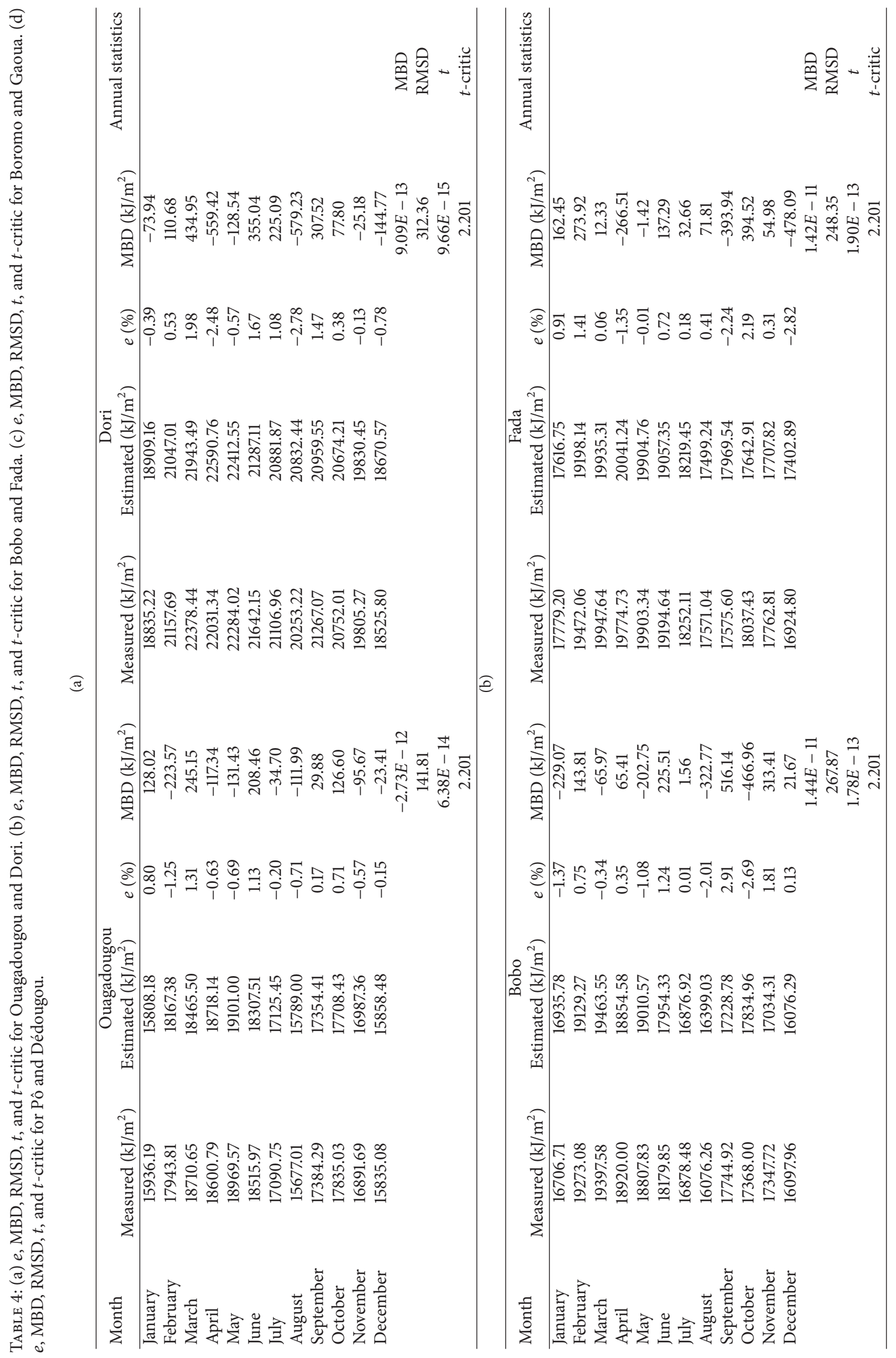




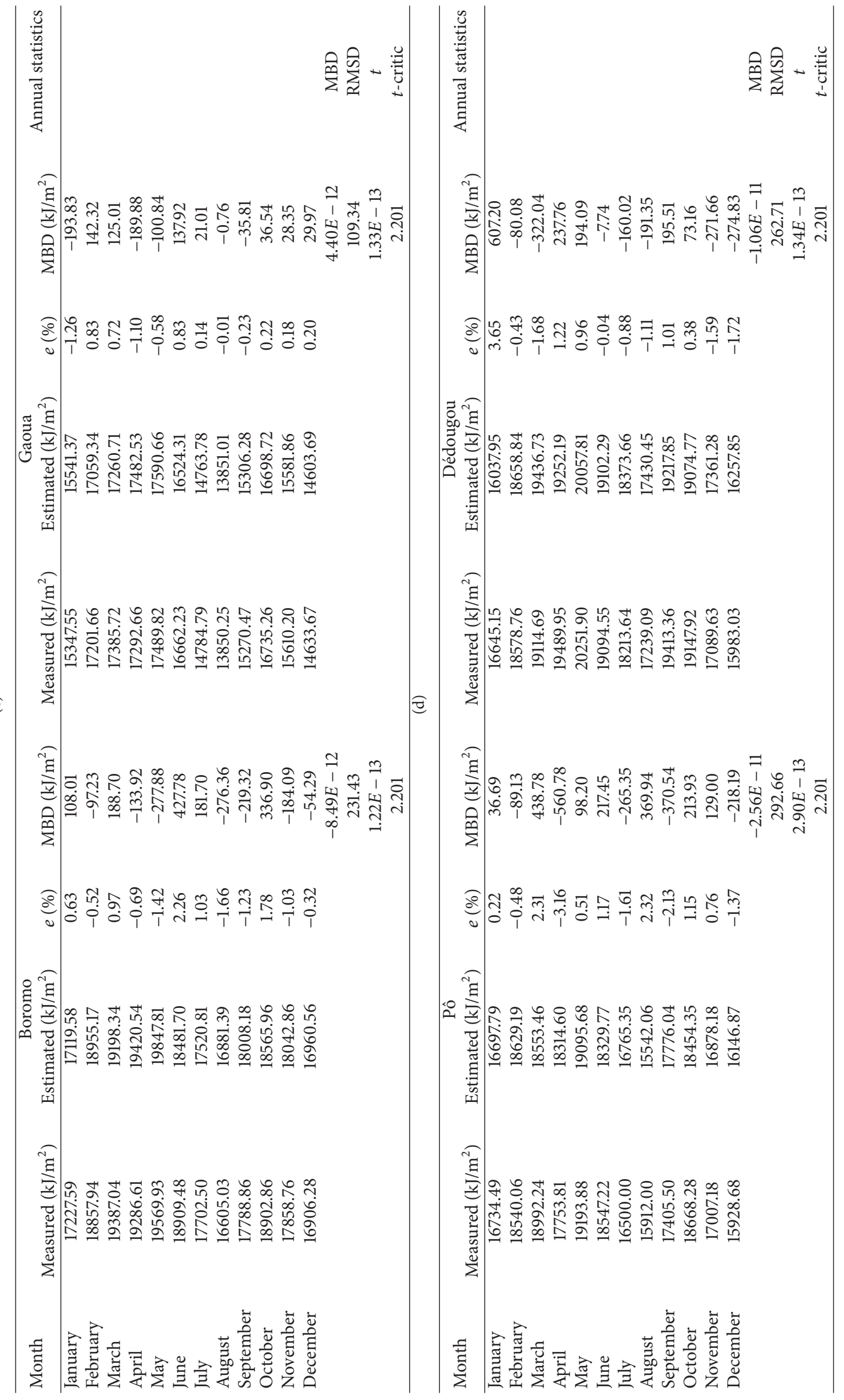


TABLE 5: Calculated and estimated quantities along with the error based on relation (18).

\begin{tabular}{lcccccccc}
\hline Quantities & Ouaga & Dori & Bobo & Gaoua & Fada & Boromo & Pô & Dédougou \\
\hline Calculated & 0.49 & 0.59 & 0.50 & 0.45 & 0.51 & 0.52 & 0.50 & 0.52 \\
Correlated & 0.52 & 0.58 & 0.48 & 0.44 & 0.51 & 0.51 & 0.49 & 0.51 \\
$e(\%)$ & -6.12 & 1.69 & 4.00 & 2.22 & 1.92 & 1.92 & 2.00 & 1.92 \\
\hline
\end{tabular}

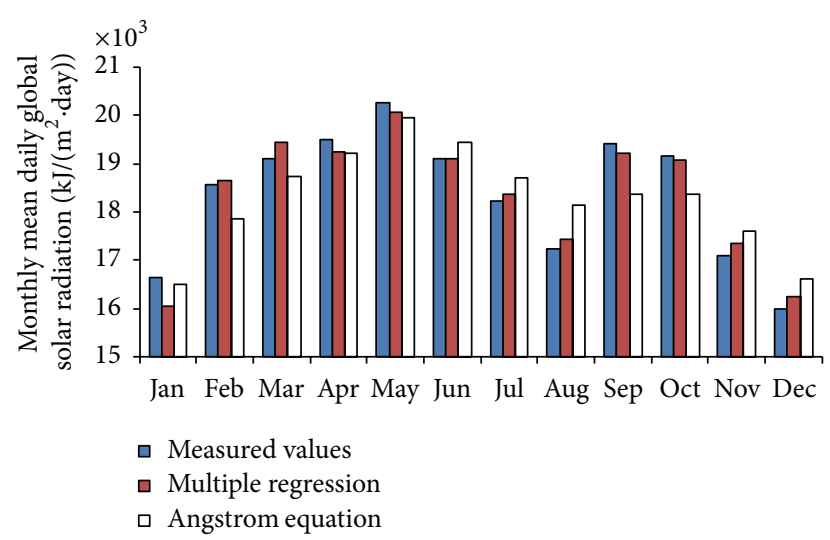

FIGURE 6: Comparison between measured and correlated values at Dédougou.

For the station of Ouagadougou, the relative error varies between $-1.25 \%$ and $1.31 \%$ while the RMSD is estimated to be $141.81 \mathrm{~kJ} / \mathrm{m}^{2}$. For Dori station, the relative error is comprised between $-2.78 \%$ and $1.98 \%$ and the RMSD is equal to $312.36 \mathrm{~kJ} / \mathrm{m}^{2}$. All these results are in the acceptable margin. We obtained small errors because the values simulated are compared with the average of measurement data over the period of the study (1977-2006). We would obtain higher errors if we carried out the comparisons with the measured data for unspecified year.

The relative errors vary between $-2.69 \%$ and $2.91 \%$ and between $-2.82 \%$ and $2.19 \%$, respectively, for the stations of Bobo and Fada while the RMSD are equal to $267.87 \mathrm{~kJ} / \mathrm{m}^{2}$ and $248.35 \mathrm{~kJ} / \mathrm{m}^{2}$ for the same stations. Once again, the margin error is acceptable.

For the station of Boromo, the relative error fluctuates between -1.66 and $2.26 \%$ while the RMSD is equal to $231.43 \mathrm{~kJ} / \mathrm{m}^{2}$. The relative error varies between -1.26 and $0.83 \%$ and the RMSD is equal to $109.34 \mathrm{~kJ} / \mathrm{m}^{2}$ for the station of Gaoua. Once again these quantities are acceptable.

For the two stations, Pô and Dédougou, the respective relative errors vary between $-3.16 \%$ and $2.32 \%$ and between $-1.72 \%$ and $3.65 \%$ while the RMSD are equal to $292.66 \mathrm{~kJ} / \mathrm{m}^{2}$ and $262.71 \mathrm{~kJ} / \mathrm{m}^{2}$, respectively. The margin is acceptable. The MBD for the eight stations is comprised between $10^{-11} \mathrm{~kJ} / \mathrm{m}^{2}$ and $10^{-13} \mathrm{~kJ} / \mathrm{m}^{2}$.

4.4. Correlation between the Average Daily Ratio of Sunshine Duration, the Index of Clearness, and the Latitude and Longitude. Equation (18) is obtained by substituting the values of the regression coefficients and the parameters in relation (12). This equation is valid nationwide and can be utilized to compute the global solar radiation for the stations measuring the sunshine duration. Consider

$$
\frac{\bar{H}}{\overline{H_{o}}}=0.2689-0.3108 \frac{\bar{n}}{\bar{N}}+2.2147 \phi-0.2729 L
$$

where $L$ (in radian) stands for the longitude and the other parameters have been defined already.

The value of 0.94 for the correlation coefficient $R$ is an indication of good correlation between the parameters. Table 5 gives the calculated and the estimated values of (18) and the corresponding relative error on the indexes of clearness. These errors vary from $-6.12 \%$ for the station at Ouagadougou to $4.00 \%$ for the station at Bobo, which is an indication of good agreement between estimated and calculated values.

\section{Conclusions}

Besides the indication of the presence of aerosols in the atmosphere, we established a correlation relation between the global radiation and five geographical and meteorological parameters for eight stations disseminated throughout the country. This correlation of the global radiation intensity shows particularly its dependency with the latitude, as the higher the latitude, the greater the global radiation. However, this trend no longer stands around urban area like Ouagadougou, which experiences lower radiation than Boromo. Another main contribution is the establishment of a relation of correlation which is valid for the entire country. Therefore, for better calibration of solar equipment, care must be made in gathering solar radiation data. For instance in Burkina Faso, not only are the meteorological stations scarce, but also they lack direct radiation measurement equipment which makes it difficult to quantify this parameter, known to be very important for the calibration of solar thermal technologies. Although the correlation equations of direct and diffuse radiation exist in the literature, they need to be rather inferred from the measurements of the country's stations.

This work can be itself extended by incorporating the influence of parameters such as the atmospheric pressure and the dew point temperature or by choosing a reference year. The actual results will be of great importance for the quantification of the global solar radiation, especially for those stations which are only measuring solar sunshine duration. Finally, the correlation relations obtained will facilitate the estimation of the solar systems performances. 


\section{Conflict of Interests}

The authors declare that there is no conflict of interests regarding the publication of this paper.

\section{Acknowledgment}

The authors would like to thank the Head of the National Meteorological Service, for fruitful discussion and for giving graciously precious weather data.

\section{References}

[1] A. K. Katiyar and C. K. Pandey, "A review of solar radiation models-part I," Journal of Renewable Energy, vol. 2013, Article ID 168048, 11 pages, 2013.

[2] C. K. Pandey and A. K. Katiyar, "Solar radiation: models and measurement techniques," Journal of Energy, vol. 2013, Article ID 305207, 8 pages, 2013.

[3] A. Angstrom, "Solar and terrestrial radiation. Report to the international commission for solar research on actinometric investigations of solar and atmospheric radiation," Quarterly Journal of the Royal Meteorological Society, vol. 50, no. 210, pp. 121-126, 1924.

[4] J. K. Page, “The estimation of monthly mean values of daily total short wave radiation on-vertical and inclined surfaces from sun shine records for latitudes 400 N-400 S," Proceedings of the United Nations Conference on New Sources of Energy, vol. 98, no. 4, pp. 378-390, 1961.

[5] J. A. Prescott, "Evaporation from water surface in relation to solar radiation," Transactions of the Royal Society of South Australia, vol. 64, pp. 114-118, 1940.

[6] S. V. Tahâş, D. Ristoiu, and C. Cosma, "Trends of the global solar radiation and air temperature in Cluj-Napoca, Romania (19842008)," Romanian Journal in Physics, vol. 56, no. 5-6, pp. 784789, 2011.

[7] T. Khatib, A. Mohamed, K. Sopian, and M. Mahmoud, "Solar energy prediction for Malaysia using artificial neural networks," International Journal of Photoenergy, vol. 2012, Article ID 419504, 16 pages, 2012.

[8] A. A. Sabziparvar, "General formula for estimation of monthly mean global solar radiation in different climates on the south and north coasts of Iran," International Journal of Photoenergy, vol. 2007, Article ID 94786, 7 pages, 2007.

[9] H. Li, F. Cao, X. Wang, and W. Ma, "A temperature-based model for estimating monthly average daily global solar radiation in China," The Scientific World Journal, vol. 2014, Article ID 128754 , 9 pages, 2014.

[10] E. Quansah, L. K. Amekudzi, K. Preko et al., "Empirical models for estimating global solar radiation over the Ashanti Region of Ghana," Journal of Solar Energy, vol. 2014, Article ID 897970, 6 pages, 2014.

[11] K. Skeiker, "Correlation of global solar radiation with common geographical and meteorological parameters for Damascus province, Syria," Energy Conversion \& Management, vol. 47, no. 4, pp. 331-345, 2006.

[12] O. P. Singh, S. K. Srivastava, and A. Gaur, "Empirical relationship to estimate global radiation from hours of sunshine," Energy Conversion and Management, vol. 37, no. 4, pp. 501-504, 1996.
[13] I. Sezai and E. Taşdemiroğlu, "Evaluation of the meteorological data in Northern Cyprus," Energy Conversion and Management, vol. 36, no. 10, pp. 953-961, 1995.

[14] A. A. Trabea and M. A. M. Shaltout, "Correlation of global solar radiation with meteorological parameters over Egypt," Renewable Energy, vol. 21, no. 2, pp. 297-308, 2000.

[15] J. C. Ododo and A. Usman, "Correlation of total solar radiation with common meteorological parameters for Yola and Calabar, Nigeria," Energy Conversion \& Management, vol. 37, no. 5, pp. 521-530, 1996.

[16] S. Neske, "About the relation between sunshine duration and cloudiness on the basis of data from Hamburg," Journal of Solar Energy, vol. 2014, Article ID 306871, 7 pages, 2014.

[17] A. Dumas, A. Andrisani, M. Bonnici et al., "A new correlation between global solar energy radiation and daily temperature variations," Solar Energy, vol. 116, pp. 117-124, 2015.

[18] A. J. Garané, Climatologie du rayonnement solaire global du Burkina Faso, Niamey, Niger [Mémoire de fin d'Études d'Ingénieurs], 1992.

[19] C. Baldy, Contribution à L'étude du Rayonnement Global et de la Durée D’insolation en Haute-Volta, Service Météorologigue, Ouagdougou, Burkina Faso, 1976.

[20] O. Coulibaly, 2011 Contribution à l'élaboration d'une réglementation thermique et énergétique des bâtiments au Burkina Faso, Données de base multiparamétriques et modélisation thermoaéraulique sous CoDyBa et TRNSYS [thése de doctorat], Université de Ouagadougou Burkina Faso, 2011.

[21] M. Daguenet, Les Séchoirs Solaires: Théories et Pratiques, UNESCO, Paris, France, 1982.

[22] Y. Jannot, Thermique Solaire, EIER, mars, Ouagadougou, Burkina Faso, 1993.

[23] P. J. Lunde, Solar Thermal Engineering: Space Heating and Hot Water Systems, John Wiley \& Sons, New York, NY, USA, 1980.

[24] K. M. Latha and K. V. S. Badarinath, "Seasonal variations of $\mathrm{PM}_{10}$ and $\mathrm{PM}_{2.5}$ particles loading over tropical urban environment," International Journal of Environmental Health Research, vol. 15, no. 1, pp. 63-68, 2005. 

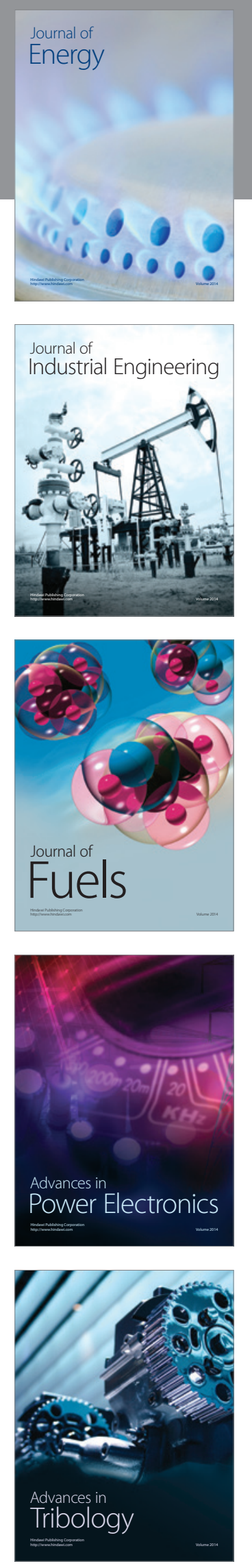
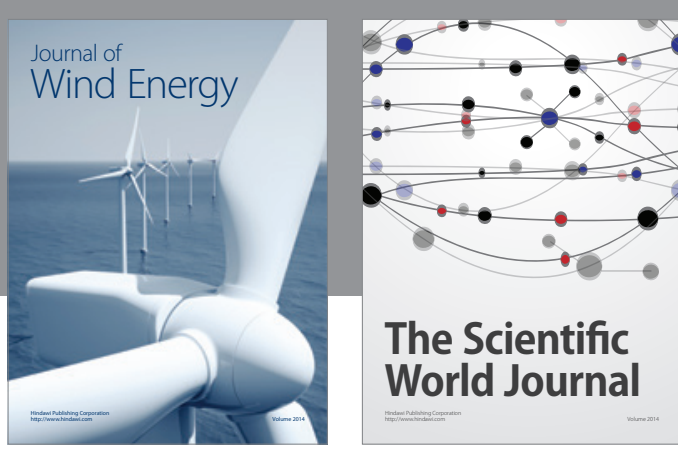

The Scientific World Journal
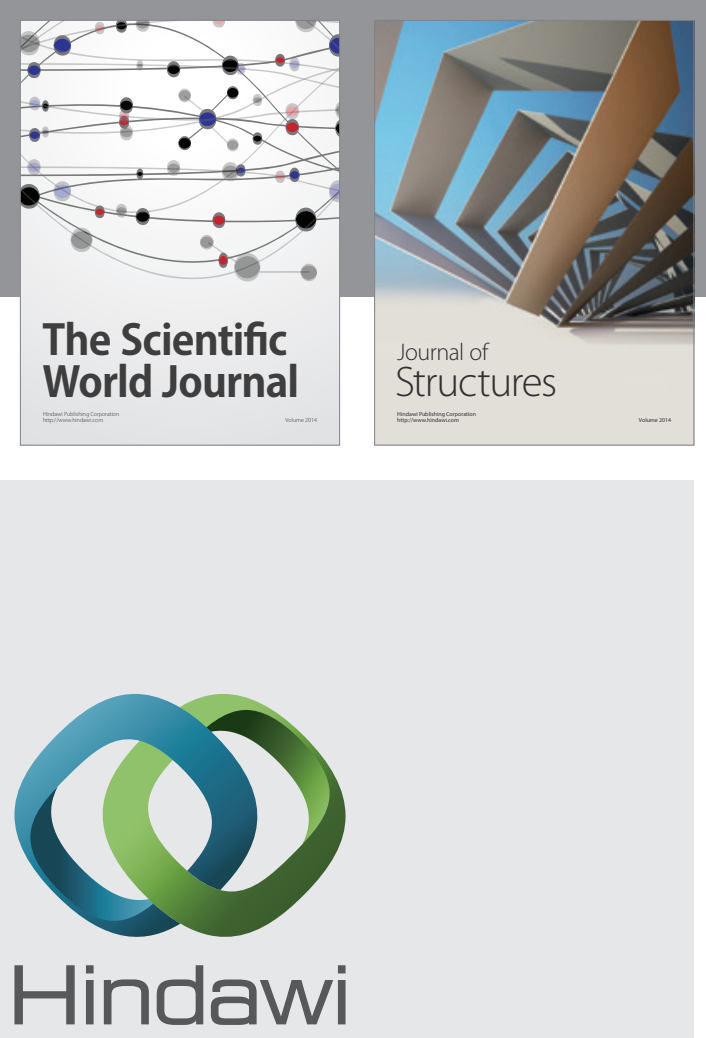

Submit your manuscripts at

http://www.hindawi.com
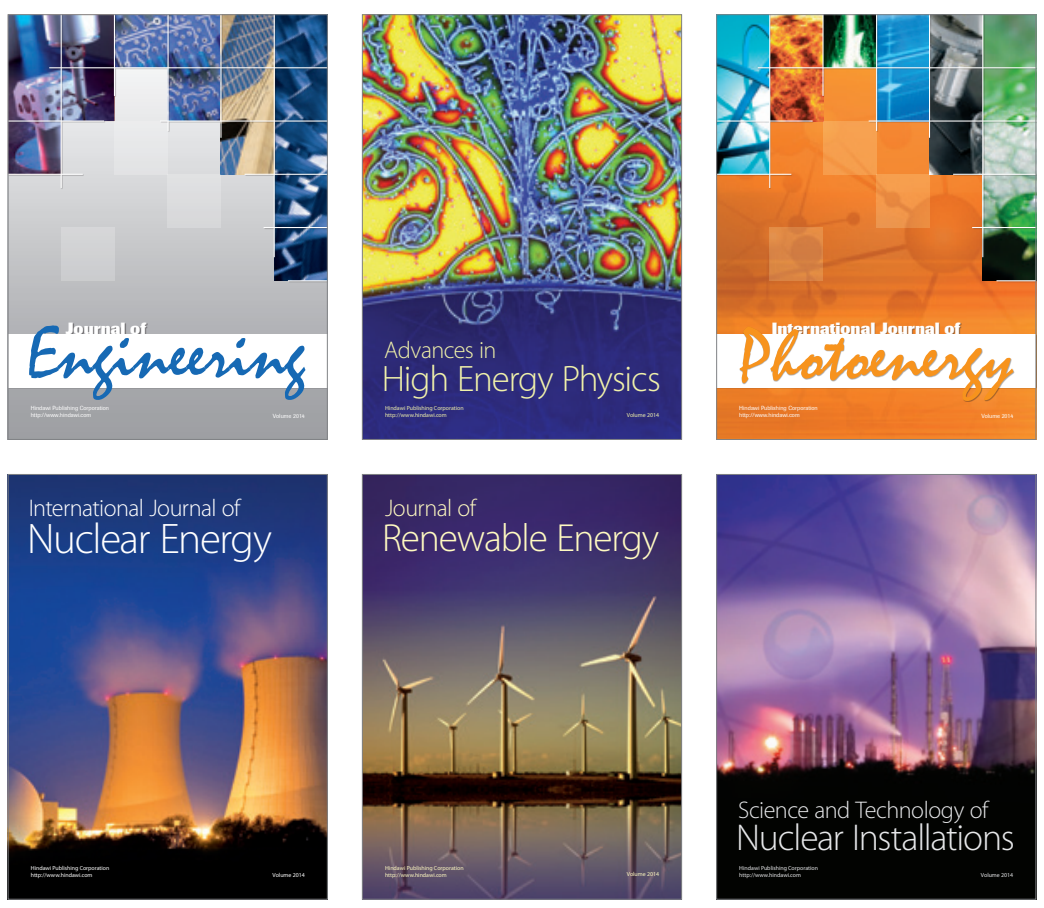
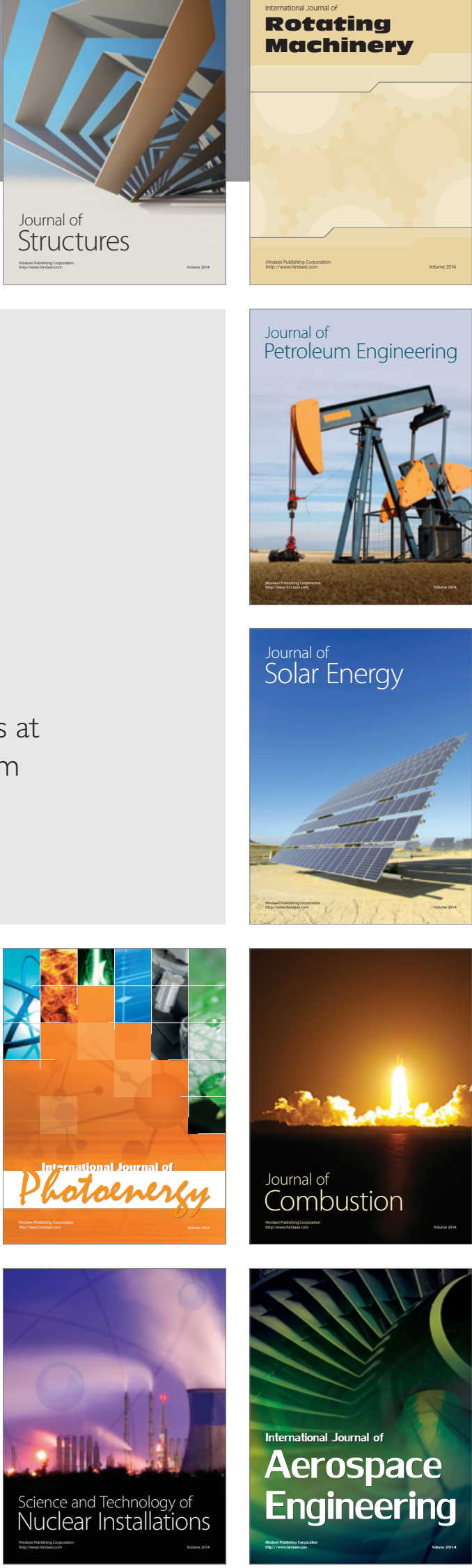